\title{
COMPARISON OF COSEISMIC IONOSPHERIC DISTURBANCE WAVEFORMS REVISITED: STRIKE-SLIP, NORMAL, AND REVERSE FAULT EARTHQUAKE
}

\author{
Mokhamad Nur Cahyadi \\ Department of Geomatics Engineering, FTSP-ITS, Kampus ITS Sukolilo, Surabaya, 60111 \\ email : cahyadi@geodesy.its.ac.id
}

\begin{abstract}
Using Total Electron Content (TEC) measurements with Global Positioning System we studied ionospheric responses to three large earthquakes with difference focal mechanism that occurred in the Sumatra Andaman 26 December 2004, North off Sumatra 11 April 2012, and North Japan 7 December 2012. These earthquakes have different focal mechanisms, i.e. high-angle reverse, strike-slip, and normal faulting, respectively. TEC responses to the Sumatra Andaman 2004 and north Japan 2012 events initiated with positive changes. On the other hand, the initial TEC changes in the Sumatra 2012 earthquake showed both positive and negative polarities depending on the azimuth around the focal area. Such a variety may reflect differences in coseismic vertical crustal displacements, which are dominated by uplift and subsidence in the Sumatra 2012 event. This phenomena has same characteristic with 1994 Kuril Arch earthquake
\end{abstract}

There are three different propagation velocity in the Sumatra 2012 earthquake, within the first $300 \mathrm{~km}$ until $430 \mathrm{~km}$, the CID propagation velocity was $\sim 3 \mathrm{~km} / \mathrm{s}$, which is equal to the secod sound speed at the height of the ionospheric Flayer. Starting from $380 \mathrm{~km}$ until $750 \mathrm{~km}$ out from the epicenter, the disturbance seems to divide into two separate perturbations, with each propagating at a different velocity, about $1 \mathrm{~km} / \mathrm{s}$ for the one and about $0.4 \mathrm{~m} / \mathrm{s}$ for the other. The apparent velocity in the Sumatra Andaman 2004 and Japan 2012 propagated $\sim 1 \mathrm{~km} / \mathrm{s}$ and $\sim 0.3 \mathrm{~km} / \mathrm{s}$, consistent with the sound speed at the ionospheric $\mathrm{F}$ layer height and internal gravity wave respectively. Resonant oscillation of TEC with a frequency of $\sim 3.7 \mathrm{mHZ}$ and $\sim 4.4 \mathrm{mHz}$ have been found in the Sumatra 2012 and Sumatra Andaman 2004 events. Those earthquakes, which occurred during a period of quiet geomagnetic activity, also showed clear preseismic TEC anomalies similar to those before the 2011 Tohoku-Oki and 2007 Bengkulu earthquake. The positive anomalies started 30-60 minutes before the earthquake to the north of the fault region. However, preseismic ionospheric anomalies of the 2012 Japan earthquake could not be observed because moment magnitude of the earthquake is smaller than Mw 8.2

Keywords : TEC, coseismic, ionospheric, GPS

\section{INTRODUCTION}

Global Positioning System (GPS) is one of the tool to observe Total Electron Content (TEC), number of electrons integrated along the line-of-sights. The first observation of coseismic ionospheric (CID) disturbances associated by earthquake was investigated by Calais and Minster (1994). Acoustic gravity wave induce variations of the ionospheric electron density (Calais and Minster, 1994; Heki and Ping, 2005; Liu et al 2004).

Cecep et al (2006) used GPS surveys in northwestern Sumatra and remote observations of the vertical motion of coral reefs, then concluded that 2004 Sumatra Andaman earthquake was generated by rupture of the Sunda subduction megathrust over a distance of 1,500 kilometres and a width of 150 kilometres. This was reverse faulting earthquake which Banerjee et al. (2005) estimated the magnitude of the earthquake did not exceed $M_{\mathrm{w}} 9.2$. Coseismic subsidence of less than a meter occurred in the Andaman except on North Andaman Island, where uplift of 0.5-1.m was estimated (Gahalaut et al,2005). On the other hand, a moment magnitude 8.6 earthquake struck off the west coast of northern Sumatra at 8:38:37 UT (Geological Survey, 2012), about 400 $\mathrm{km}$ soutwest of Aceh. The epicenter of this earthquake was (2.311 $\mathrm{N}$ and $93.063 \mathrm{E})$ in latitude and longitude. Another major $\mathrm{Mw}=8.2$ 
earthquake was occurred 2 hours after the mainshock (10:43:9 UT, $0.77 \mathrm{~N}, 92.45 \mathrm{E}$; USGS). The mechanism shows the strike-slip earthquake with tsunami risk (Ishii et al, 2012).

The Sumatra earthquake 2012 has complexity process which three different rupture occurred, it was around $500 \mathrm{~km}$ in mainshock and $100 \mathrm{~km}$ in aftershock (Meng et al, 2012). The focal mechanism element in mainshock event also has changed during 110 seconds with four different subfault, the velocity of rupture is $2.0 \mathrm{~km} / \mathrm{second}$ (Yue et al, 2012). This was one of the biggest strike-slip earthquake mechanism.

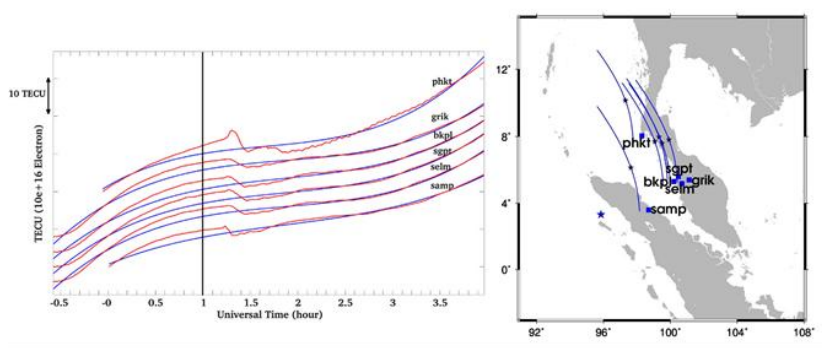

Figure 1. CID and Preseismic lonospheric Disturbance at the 2004 Sumatra Andaman

\section{DATA AND METHODS}

We used $15 \mathrm{~s}$ sampling interval from Sumatra GPS Array (SuGar) for Sumatra earthquake 2012. Those stations was installed, operated and maintained by LIPI (Indonesian Institute of Sciences) cooperated with EOS (Earth Observatory of Singapore). On the other hand, Sumatra Andaman eartquake 2004 used $30 \mathrm{~s}$ sampling from Malaysia GPS Array, and earthquake east Sendai on the December 2012 used GEONET data.

The CIDs of the 2004 andaman earthquake have been investigated by Heki et al (2006) in detail, but the preseismic ionospheric disturbances has not been studied yet. Those preseismic anomalies will be compared with another big earthquake in north Sumatra 2012 which it was the biggest strike-slip earthquake mechanism.

lonosphere response to acoustic wave can be detected in the vicinity of an epicenter of earthquake 10-15 minutes after the main shock. It propagated $\sim 800-1000 \mathrm{~m} / \mathrm{s}$ at the height of the ionosphere F-layer (equal to the sound speed).
Astafyeva et al (2009) found three different propagation velocities in the great Kuril Arc.

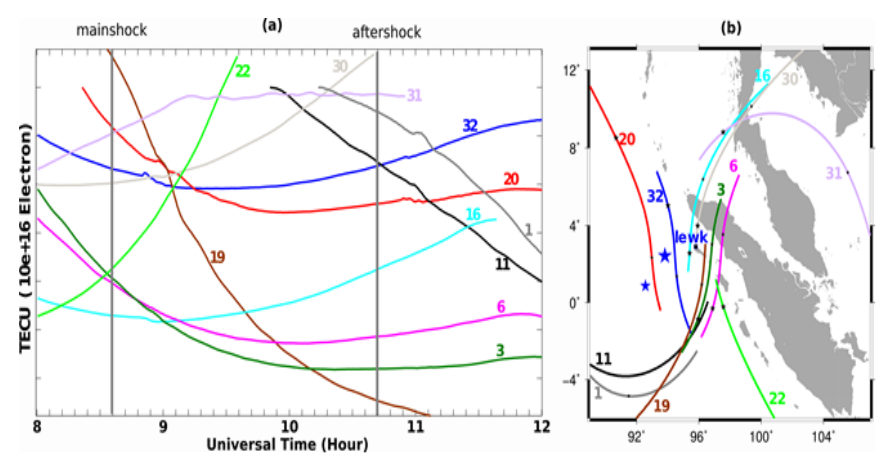

Figure 2. CID at the 2012 North Sumatra Earthquake

Earthquake of 4 October 1994 which are slow component of acoustic wave $\sim 1 \mathrm{~km} / \mathrm{s}$, the fast component of acoustic wave $\sim 4 \mathrm{~km} / \mathrm{s}$, and internal gravity wave $0.3 \mathrm{~km} / \mathrm{s}$. Heki and Ping (2005) also investigated N-S asymmetry in Japan which means northern hemisphere area. It would be important if such directivity were seen in the southern electromagnetic field of view. The velocities of propagation will be investigated also in the three earthquakes.

There are some researches regarding acoustic resonance by Choosakul et al. (2009), Saito et al. (2011). Those researches investigated TEC in Sumatra Andaman 2004 earthquake and 2011 Tohoku-Oki earthquake, respectively. Similar resonant oscillation after the 2011 Tohoku-Oki earthquake also was reported by Rolland et al., (2011) that frequencies of TEC oscillation located in 3.7-4.4 mHz. So, TEC oscillation of Sumatra Andaman event will not be evaluated in this research in detail because there was any previous researches have been already done .Because of 2012 Sumatra earthquake is M 8 class earthquake, we can expect to detect similar signals after this earthquake. The 2012 Japan earthquake is M7 class, so we estimate that there will be no TEC oscillation.

There were some research analysing precursor of earthquake i.e radon exhalation (Hauksson and Goddad, 2012; ), a propagation anomaly of VLF (Molchanov and Hayakawa, 2008), and long term preseismic ionospheric anomaly (Liu et al,2004 ; Le at al,2010;;Le $H$. et al 2013). longterm ionosphericpreseismic anomaly investigated 
reduction ionosphere density in several days before the quake which based on A 15-day running median of theTEC and the associated inter-quartile range (IQR), which are utilized as a reference for identifying abnormal signals during earthquakes (Liu et al 2004). On the other hand, there was short term preseismic anomaly introduced in Tohoku earthquake 2011 (Heki K., 2011) and Bengkulu earthquake 2007 (Cahyadi and Heki,2013). In this reseacrh we will concern to investigate short term preseismic anomaly.

\section{RESULT AND DISCUSSION}

\section{GPS TEC Data Analysis}

Global Navigation System (GPS) firstly developed by Defense Department of U.S. The signal of GPS satellite was propagated from $20,200 \mathrm{~km}$ altitude to receiver trough ionosphere. There are two frequencies $1575.42 \mathrm{MHz}$ and $1227.60 \mathrm{MHz}$. The procedure of TEC calculation follows previous research (e.g., Calais and Minster, 1995; Afraimovich et al., 2001a; ), which the carries phase in original data were converted to lengths then their differences were multiplied with a factor into TEC. The same procedure has already been done in previous research in TEC calculation (Heki et al 2006; Astafyeva and Heki,2009; Cahyadi and Heki,2013). In order to eliminate the noise and trends caused by orbital motion of the satellite, we obtained TEC variations by estimating best-fit polynomial with degree up to seven and substracting these polynomial.

For convenience number, TEC usually expressed in units of TECU (10-16 el/m2). We assumed the ionosphere as a thin layer located at the height hmax of the ionosphere F2 layer $(300 \mathrm{~km})$. In order to trace propagation of CID in the ground, we described subionospheric point (SIP), which is intersection between the receiver-satellite line of sight and the altitude of greatest electron density. The locations of the GPS stations are represented by solid rectangle marks, and the location of the epicenter is represented by an star, it can be shown at figure 1

\section{TEC Response in The Sumatra Andaman Earthquake 2004}

CID of Sumatra Andaman earthquake 2004 have been investigated by (Heki et al, 2006) in details. Clear disturbance was observed by 3 satellites which are satellite 13, 20 and 23. All SIP located in the east northern of the epicenter. The disturbance was started 12 minutes after earthquake which it was located $750 \mathrm{~km}$ from epicenter. The amplitude of the anomaly which was observed by satellite 13 around $3.9-6.7$ TECU. The highest peak was observed by satellite 13 from juml station. The difference of the response depends on the azimuth of SIP relative to the epicenter. SIP satellite 13 was located north eastern, it caused the angle wavefront become smaller. Apparent velocity showed that acoustic wave was appeared 12 minutes after earthquake. The velocity of propagation is 1.26 $\mathrm{km} / \mathrm{s}+-0.05 \mathrm{~km} / \mathrm{s}$ which it is agree with previous research by (Heki et al,2006). This velocity propagates until $1070 \mathrm{~km}$ from epicenter. The same wave was also detected by satellite number 23 which the apparent velocity is $0.81+/-0.04$ $\mathrm{km} / \mathrm{s}$. On the other hand, CIDs was observed by satellite 20 has the biggest magnitude in phkt station 7 TECU. Another apparent velocity has been been reported by Liu et al (2006), propagation of CID in the Sumatra Andaman 2004 earthquake has apparent velocity 3.6 $\mathrm{km} / \mathrm{s}$ and atmospheric gravity wave ( $360 \mathrm{~m} / \mathrm{s}$ ). They observed it by Doppler sounder array in Taiwan.The CID was followed oscillation in the phkt station by satellite 13 around two and half hours. Oscillation of CID was also found on the satellite 23 in phkt station with duration two hours. Choosakul et al (2009) has investigated frequency of the oscillation in detail with dominant frequency $\sim 3.9 \mathrm{mHz}$.

\section{TEC Response in The North Sumatra Earthquake 2012}

Cahyadi and Heki (2014) described CID in the North Sumatra earthquake in details, there was any positive TEC anomaly after $10-15$ minutes with anomaly 3.5 TECU in mainshock event, then was continued by positive anomaly again two hours later around 0.8-1.4 TECU in the aftershock event. After the impulsive enhancement with this, TEC showed a pulsation 
before become constan again. It can be understood as a response to propagating shockacoustic waves (SAW) . It agree with some previous research (Astavyeva and Heki, 2007; Cahyadi and Heki, 2012). There is also interesting in the aftershock event that lewk, bnon, sdkl and pbkr stations have positive anomalies then the value decrase but was continued again by positive anomalies. It can be understood because the coseismic vertical movements were compund by subsidence and deformation with same magnitude, were rather complicated.

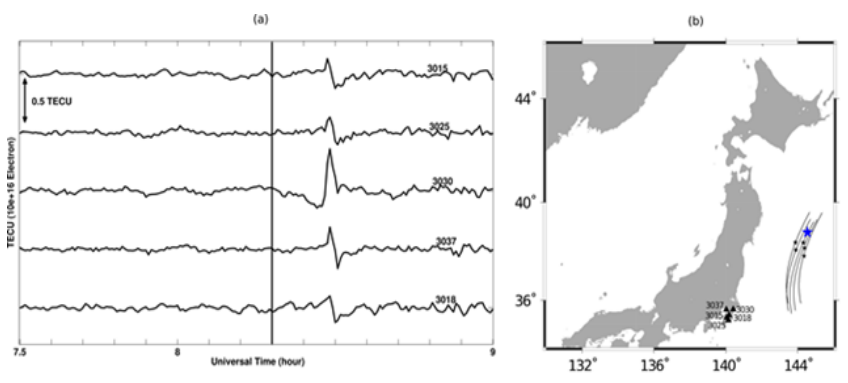

Figure 3. CID at the 2012 North Japan Earthquake

At first, 10-15 minutes after quake TEC perturbation by satellite 20 has maximum amplitude of anomaly $3.5 \mathrm{TECU}$, it was occurred at distance $380 \mathrm{~km}$ then came negative TECU after $390 \mathrm{~km}$ distance, the minimum TECU is in the $397 \mathrm{~km}$ then came normal after $400 \mathrm{~km}$. Starting from 303 in lewk station km to $500 \mathrm{~km}$ away from the epicentre in the ptlo station, the disturbance seems to split into two separate waves which further differ by their dynamic characteristic, one wave propagates farther while the other one fades and becomes almost indiscernible at distance of about $500 \mathrm{~km}$. The shape of the signal has similarity with Kurile Arc earthquake in 1994 which was already investigated by Astafyeva et al (2009). There was any initial disturbance propagates with apparent velocity about $2.48+/-0.34 \mathrm{~km} / \mathrm{s}$ that equal with second sound apparent velocity at the height of the ionosphere F-layer. It was located at the distance propagation from $300 \mathrm{~km}$ until $430 \mathrm{~km}$. After 45 minutes, separation of the component velocities are clearly seen which are $1+/-0.04$ $\mathrm{km} / \mathrm{second}$ as first sound velocity from distance $380 \mathrm{~km}$ until $750 \mathrm{~km}$ and $0.49 \mathrm{~km}+/-0.14 \mathrm{~km} / \mathrm{s}$ as internal gravity wave velocity from $350 \mathrm{~km}$ distance until $390 \mathrm{~km}$.
Another anomaly also was clearly shown by satellite 32 which the SIP located in the east northern of the epictenter, which the anomalies 1.8-2.6 TECU in mainshock event and $0.3-1.2$ TECU in the aftershock event. The amplitude of anomaly by satellite 20 was bigger than satellite 32 , even the satellite 32 was closer to epicenter. It can be understood because the directivity effect. In the sourthen hemisphere of the electromagnetic field view the beam will move to south direction and it be reverse in the northen hemisphere of the geomagnetic field view. Propagation velocity of CID monitored by satellite 32 also show acoustic wave, the velocity is $\sim 0.8 \mathrm{~km} / \mathrm{s}$, propagation of gravity wave was started from $400 \mathrm{~km}$ distance until $1400 \mathrm{~km}$ around Andaman Island. This propagation speed was mainly in mainshock event.

It was noted that the initial TEC variation anomalies in this earthquake was started by positive anomalies as reverse faulting mechanism even this was strike slip event. It was reported by Bosai-Japan (National Research Institute for Earth Science and Disaster Prevention) that rake angle component in this earthquake 15 degree, means $\sim 1 / 4$ of the moment released as reverse faulting, equivalent to a Mw8.2 thrust event. Resonant oscillations of the atmosphere with a frequency of $\sim 3.87 \mathrm{mHz}$ were found to follow the CID for one and half hour in umlh station by satellite 20 .

The long duration also indicates as effect of a nontransient process like resonance (Choosakul et al, 2009). The acoustic wave propagated vertically into F2 layer ionosphere, some these waves reflect downward in the thermosphere and interfere with upward propagating waves (Tahira, 1995; Saito et al,2011).

The $\mathrm{Kp}$ index and the Dst index are stable and quiet on day when earthquake occurred, the same situation was not different in some days before and after earthquake occurred. This suggests that the anomalous TEC enhancement only take place around the epicenter and it is unlikely to be related to space weather changes and/or magnetic activities. We confirmed that no solar flares are reported on 11 April 2012 in the 
Web page of the Space Environment Center (http://www.sec.noaa.gov).

\section{Japan North earthquake 7 Desember 2012}

The TEC time series over the 1.5 hours interval from 07:30-09:00 UT have been low-cut filtered by substracting degree polynomial fit to them. Figure 2 described TEC time series and IPP trajectories at 3030 station. Dst index on that day is quiet in range -4 until $4 \mathrm{nt}$, such distubances are caused by the earthquake rather than space weather effect. There are several satellites seen on that time is satellite number $24,2,10,8,5,26$ and 9. The IPP of satellite number 8 moved from south to north in the western of the epicenter.

This satellite has trajectory quet close to the epicenter. The positive anomaly is about 0.35 TECU with duration 144 seconds then the pulse will normal again. The anomaly starts 10 minutes after earthquke occurred. Almost of the anomaly iniated by positive anomaly except station 3030 , the amplitude was itiated by negative value, then the TEC start to positive anomaly. The positive anomalies was occurred in the distance $300 \mathrm{~km}$ from epicenter. The apparent velocity of the disturbance is about $0.36 \mathrm{~km} / \mathrm{s}$, which is as fast as the known of propagation of gravity wave. The signal of this earthquake is dominated by uplift. The different result was showed by Astavyeva and Heki (2009) in Kuril Arc earthquake 2007 which was also normal earthquake. The CIDs in this earthquake was dominated by positive and negative signal.

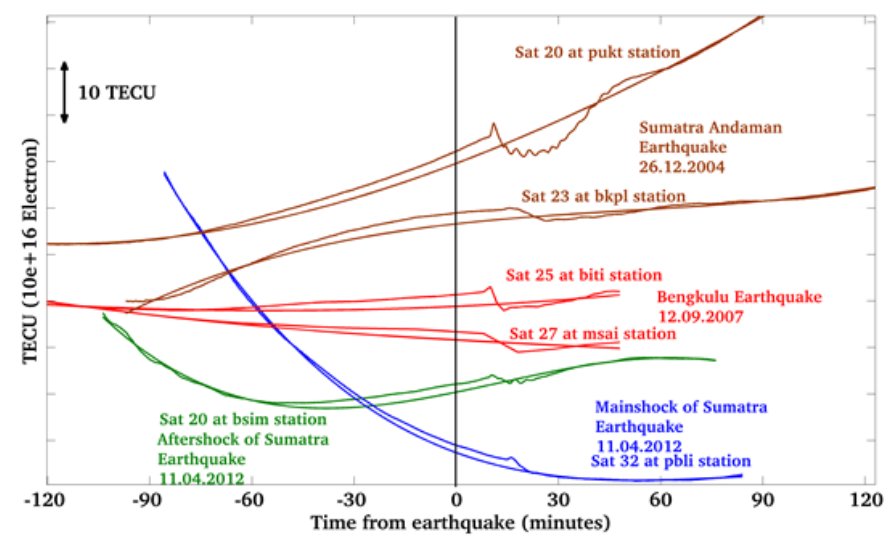

Figure 4. Preseismic lonospheric Disturbance at several earthquakes

\section{Comparison of the Amplitude}

The are three types of earthquake was investigated in this research as described above, fig 4 try to compare the magnitude of the anomaly in one graph. Satellite 23 measured the positive anomaly in Sumatra Andaman 2004 with the highest value.

It can be understood because the energy of the moment magnitude of this earthquake is the biggest one, also there is interesting result that the 2012 Sumatra earthquake has positive anomaly even it is the strike-slip earthquake. Initial positive TEC changes also was found on the 2012 Japan earthquake, it was the smallest amplitude of TEC anomaly because of moment magnitude of the earthquake.

\section{Preseismic TEC}

Long term variation before earthquakes have been analyzed by some researchers, it usually TEC density was decrease 3-4 days before earthquake, forexample in Chi-chi earthquake (Liu et al, 2001), Taiwan (Liu et al,2004), Sumatra Andaman 2004 (Liu et al, 2008; C.Y Liu et al, 2010).
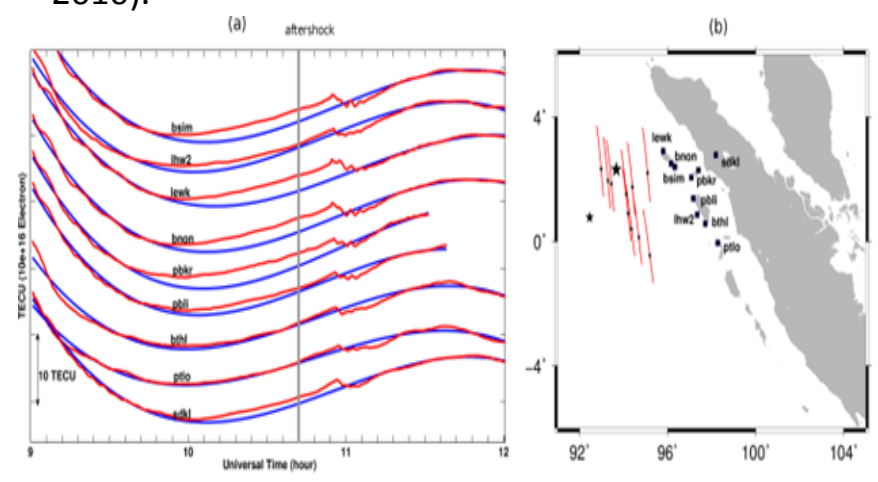

Figure 5. Preseismic lonospheric Disturbance at the 2012 North Sumatra Earthquake

In this research, we focus on the short term anomaly disturbances which the procedure follows Ozeki and Heki (2010) and Heki (2011) i.e., modelling the vertical TEC as a cubic polynomial of time as reference. The anomaly usually was appeared $\sim 40-60$ minutes before earthquake. We exclude start $\sim 40$ minutes before earthquake from the model during $\sim 60$ minutes. Excluding time in the Sumatra 2012 earthquake is 08.00-09.15 UT for mainshock event and 10.00-11.15 UT for aftershock event. 
Preseismic TEC enhancement in Sumatra earthquake 2012 was observed by satellite 32 and 20 which there were any TEC enhancement 60 minutes before earthquake. It can be showed either in the mainshock and aftershock event ( Fig 3). The enhanced TEC anomalies recover after CIDs, we can find this phenomena in all of the stations. this can be understood as the combined result of physical and/or chemical processes, i.e., the mixing of ionosphere by acoustic waves and recombination of ions transported downward (Saito et al ., 2011; Kakinami et al ., 2012).

Preseismic anomaly by satellite 20 seems bigger than satellite 32 because satellite 20 has closer SIP to epicenter. Another important point was preseismic enhancement at ptlo and bthl which was smaller (by satellite 20 in aftershock event). It can be understood as the directivity (N-S asymmetry of propagation) of CIDs effect. Long term preseismic anomaly in Sumatra Andaman 2004 earthquake has been evaluated by Liu et al (2010). They found that GPS-TEC around the epicenter was significanly reduced 5 days before earthquake. The reason behind this phenomena was that seismo-environtment changes around the epicenter during the earthquake preparation period.

Short term preseismic enhancement in the Sumatra Andaman 2004 was observed by satellite 20 and 23 . It was consistent with previous research (Heki, 2011; Cahyadi and Heki,2013) that enhanced TEC was started $\sim 40-$ 60 minutes before the earthquake. The model (blue line) was obtainded from cubic polynomial which time duration from....-...UT was excluded from the model. The diffference TEC background on the both graph is caused by azmiuth SIP relative to the epicenter. All SIP of satellites 20 and 23 was located on the north of fault.

Preseismic enhancement in the Sumatra Andaman 2004 also appeared 60 minutes before the earthquake. It was clearly showed by satellite 20 and 23. Fig 1 and 3 showed that the biggest preseismic TEC was observed by satellite 20 in phkt station. Comparison preseismic TEC enhancement from Fig 4 showed that preseismic enhancement in the Sumatra earthquake 2012 is comparable with other earthquake even this is the strike slip earthquake. All of the preseismic result above can be concluded that earthquakes with bigger than 8.3 Mw have preseismic enhancement

\section{CONCLUSION}

The CIDs from three earthquakes shown that have characteristic of initial anomalies. Waveforms of three earthquakes is initiated by positive signal, but in the 2012 Sumatra aftershock earthquake has similarity with 2007 Kuril Arc earthquake with positive and negative anomalies. The other aspect in this paper is CID, preseismic enhancement anomaly, propagation speed, azimuthal asymmetry of propagation specially in southern electromagnetic of view, also investigated comparison relative between amplitude and CID by normalisation with TEC background in recent area (GIM).

Short term preseismic of 2012 North Sumatra and 2004 Sumatra Andaman have similar behaviour with the 2011 Tohoku-Oki and 2007 Bengkulu earthquake. The behavior of TEC with the same satellite-station combination over 2 months suggests that the occurrences of similar anomalies are infrequent especially during geomagnetic quiescence. Hence it is not likely that space weather is responsible for the observed short-term preseismic TEC changes. This, together with other cases (Heki, 2011), suggests that the observed anomaly is relevant to the earthquake seems same phenomena with kuril arc earthquake (astavyeva and heki,2009)

A clear CID was observed in the both Sumatra earthquake, second acoustic wave and internal gravity wave was also found in the 2012 Sumatra earthquake. On the other hand, internal gravity wave was detected in the 2012 Japan earthquake. The directivity (north-south asymmetry of propagation) of CID in the southern hemisphere was clearly proofed due to $\mathrm{N}-\mathrm{S}$ asymmetry of the network which the beam moved from south to north in the southern electromagnetic field of view. This was observed in the 2012 Sumatra earthquake 2012. Resonant oscillation of the atmosphere with frequency of 
$\sim 3.87 \mathrm{mHz}$ were found to follow the CID and last one half hour in this earthquake.

\section{REFERENCES}

Astafyeva, E. \& Heki, K., 2009.Dependence of waveform of near-field coseismic ionospheric

disturbances on focal mechanisms, Earth Planets Space, 61, 939-943.

Astafyeva, E. \& Heki, K., 2011. Vertical TEC over seismically active region during low solar activity, J.

Atm. Terr. Phys., 73, 1643-1652.

Astafyeva, E., Heki, K., Kiryushkin, V., Afraimovich, E. \& Shalimov, S., 2009. Two-mode longdistance propagation of coseismic ionosphere disturbances, J. Geophys. Res., 114, A10307, doi: 10.1029/2008JA013853.

Astafyeva, E., Lognonné, P. \& Rolland, L., 2011.First ionosphere images for the seismic slip of the Tohoku-oki Earthquake, Geophys. Res. Lett., 38, L22104, doi:10.1029/2011GL049623.

Banerjee, P., F. F. Pollitz, and R. Bürgmann (2005), The size and duration of the SumatraAndaman Earthquake from far-field static offsets, Science, 308, 1769-1772.

Cahyadi, M. N., and K. Heki (2013), Ionospheric disturbances of the 2007 Bengkulu and the 2005 Nias earthquakes, Sumatra, observed with a regional GPS network, J. Geophys. Res. Space Physics, 118, doi:10.1002/jgra.50208.

Calais, E. \& Minster, J. B., 1995. GPS detection of ionospheric perturbations following the January 17 ,

1994, Northridge earthquake, Geophys. Res. Lett., 22, 1045-1048, doi:10.1029/95GL00168.

Choosakul, N., Saito, A., lyemori, T. \& Hashizume, M., 2009.Excitation of 4-min periodic ionospheric variations following the great Sumatra-Andaman earthquake in 2004, J.
Geophys. Res., 114, A10313, doi:10.1029/2008JA013915.

Heki, K. \& Ping, J.-S., 2005. Directivity and apparent velocity of the coseismic ionospheric disturbances observed with a dense GPS array, Earth Planet. Sci.

Lett., 236, 845-855.

Kakinami, Y. et al. (2012), Tsunamigenic ionospheric hole, Geophys. Res. Lett., 39, L00G27, doi:10.1029/2011GL050159.

Liu, J.-Y., Y. I. Chen, Y. J. Chuo, and H. F. Tsai (2001), Variations of ionospheric total electron content during the Chi-chi earthquake, Geophys. Res. Lett., 28, 1383-1386.

Liu, J. Y. et al. (2009), Seismoionospheric GPS total electron content anomalies observed before the 12 May 2008 Mw7.9 Wenchuan earthquake, J.

Geophys. Res., 114, A04320, doi:10.1029/2008JA013698.

Liu, J.-Y., Y. I. Chen, Y. J. Chuo, and H. F. Tsai (2001), Variations of ionospheric total electron content during the Chi-chi earthquake, Geophys. Res. Lett., 28, 1383-1386.

Liu, J. Y. et al. (2009), Seismoionospheric GPS total electron content anomalies observed before the 12 May 2008 Mw7.9 Wenchuan earthquake,

J. Geophys. Res., 114, A04320, doi:10.1029/2008JA013698. Ozeki, M. \& Heki, K., 2010. Ionospheric holes made by ballistic missiles from North Korea detected with a Japanese dense GPS array, J. Geophys. Res., 115, A09314, doi:10.1029/2010JA015531.

Saito, A. et al., 2011. Acoustic resonance and plasma depletion detected by GPS total electron content observation after the 2011 off the Pacific coast of Tohoku Earthquake, Earth Planets Space, 63, 863-867.

Tahira, M. 1995. Acoustic resonance of the atmospheric at $3.7 \mathrm{mHz}$, J. Atmos. Sci., 52, 2670-2674. 